This manuscript has been accepted by IEEE for publication (C) 2009 IEEE. Personal use of this material is permitted. Permission from IEEE must be obtained for all other uses, in any current or future media, including reprinting/republishing this material for advertising or promotional purposes, creating new collective works, for resale or redistribution to servers or lists, or reuse of any copyrighted component of this work in other works. The full reference is:

\title{
Effect of Long-Time Electrical and Thermal Stresses upon the Endurance Capability of Cable Insulation Material
}

\author{
A. Tzimas, S.M. Rowland, L. A. Dissado, M Fu and U. H. Nilsson
}

IEEE Transaction on Dielectrics and Electrical Insulation, Vol 16, No. 5, (2009)

pp. 1436-1443

DOI: 10.1109/TDEI.2009.5293958 


\title{
Effect of long-time electrical and thermal stresses upon the endurance capability of cable insulation material
}

\author{
Antonios Tzimas and Simon Rowland \\ The School of Electrical and Electronic Engineering \\ The University of Manchester \\ PO Box 88, Manchester, M60 1QD, UK \\ Leonard A. Dissado \\ Department of Engineering \\ University of Leicester \\ Leicester, LE1 7RH, UK \\ Mingli Fu \\ Technology Centre, AREVA T\&D \\ Stafford, ST17 4LX, UK \\ Ulf H. Nilsson \\ Borealis AB \\ Stenungsund, Sweden
}

\begin{abstract}
This paper presents the results of endurance tests that have been carried out on crosslinked polyethylene (XLPE) cable peelings. The peelings were taken from cables that were manufactured from a single batch of XLPE and subjected to electrical (up to 28 $\mathrm{kV} / \mathrm{mm})$, thermal $\mathrm{T}=363 \mathrm{~K}\left(90{ }^{\circ} \mathrm{C}\right)$ and electro-thermal stressing for at least 5000 hours. The endurance tests of the peelings (thickness $150 \mu \mathrm{m}$ ) were carried out at the same temperature of $T=363 \mathrm{~K}$ as the thermally stressed cable, but at two different ac electrical fields of 55 and $70 \mathrm{kV} / \mathrm{mm}$. The resulting life data for the different sample sets are compared to one another and to that of peelings taken from unaged cables. Weibull analysis of the failures shows that only peelings from cables that had experienced a thermal stress component during their time of stressing as a cable, exhibited a statistically significant reduction in endurance capability. Possible reasons for this reduction of life are discussed.
\end{abstract}

Index Terms - Thermal stress effect, XLPE, endurance testing, cable peelings, Weibull statistics.

\section{INTRODUCTION}

THe replacement of oil-filled cable insulation by polymeric materials and the necessity to ensure equivalent performance and reliability has led to a large amount of research into ageing mechanisms during service and accelerated ageing [1]. Now that such insulating materials have been in service for several decades the opportunity exists to ascertain their current condition so that decisions can be taken regarding replacement. There is therefore a need for an understanding of the degradation process and an identification of diagnostic factors. The EU-sponsored ARTEMIS programme [2] was an attempt to resolve these problems involving the collaboration of a number of research institutes. A feature of this programme was that $90 \mathrm{kV}$ crosslinked- polyethylene (XLPE) cables were manufactured by two different companies using exactly the same batch of XLPE. Samples from the cables were placed under electrical, thermal, and electro-thermal stress for varying lengths of time, up to about two years, after which their insulation was peeled. The peeling was then subjected to a number of diagnostic measurements designed to characterize the state of the insulating material in comparison to its state in an unstressed (i.e. unaged) cable. An analysis of the results did not show significant differences in the properties that were examined. The ARTEMIS project demonstrated a very low rate of degradation of the cable materials in spite of the use of very high electric stress levels at elevated temperatures. Nevertheless, it did provide a definite indication of the techniques that should be used to evaluate the state of the insulation, one of which is its endurance capability. This is reported here. 
Endurance life data of unstressed peelings for electric fields varying from 30 to $80 \mathrm{kV} / \mathrm{mm}$ (rms) and two temperatures 293 $\left(20^{\circ} \mathrm{C}\right)$ and $363 \mathrm{~K}\left(90^{\circ} \mathrm{C}\right)$ was generated as part of the ARTEMIS programme [3]. This data demonstrates that the endurance life of the peelings from an unstressed cable is lower at the higher temperature in comparison to the lower one. Moreover, this difference is greater at lower electric fields compared to the higher ones where the difference is insignificant. In this work we investigate whether or not XLPE insulation peelings from cable sections with different electro-thermal histories show a statistically significant change in endurance life compared to those taken from unstressed cable. In other words we determine whether or not the electro-thermal stressing that the XLPE material experienced as a cable has altered its inherent endurance capability and whether or not this change is reflected in its peelings.

\section{EXPERIMENTAL}

\subsection{TEST PROTOCOL}

The endurance tests, reported here, were conducted under two different conditions $\mathbf{A}$ and $\mathbf{B}$ as is shown in

Table 1. The endurance test under the condition $\mathbf{A}$ was carried out more than once, and the number of the relevant sample set is denoted by the subscript. Part of this data is also reported by [3]. The alphabetical order of the endurance tests also corresponds to the order in which the tests were carried out. The first test, $\mathbf{A}$, was carried out with an AC electric field of $70 \mathrm{kV} / \mathrm{mm}(\mathrm{rms})$ and a temperature of $363 \mathrm{~K}$. The second test, B, was conducted at the same temperature but with a lower electric field of $55 \mathrm{kV} / \mathrm{mm}$ (rms). The materials that were used in each test are listed in Table 2 along with their stressing pre-histories as a cable during the ARTEMIS programme.

The statistical analysis is carried out using extreme value Weibull statistics according to the IEEE P930 standard guide [4]. The expression for the cumulative density function for the two-parameter Weibull distribution is:

$$
F(t ; \alpha, \beta)=1-\exp \left\{-\left(\frac{t}{\alpha}\right)^{\beta}\right\}
$$

where:

$t$ is the measured variable, usually time to break down or the breakdown voltage,

$F(t)$ is the probability of failure at a voltage or time less than or equal to $t$,

$\alpha$ is the scale parameter defining a characteristic value of the measured variable $t$ and is positive, and

$\beta$ is the shape parameter and is a positive number.
Table 2. Materials used for the endurance tests defined in Table $\mathbf{1}$ and their pre-history as a cable.

\begin{tabular}{|c|c|c|c|c|}
\hline \multirow[b]{2}{*}{$\begin{array}{l}\text { Ref. } \\
\text { name }\end{array}$} & \multirow[b]{2}{*}{ 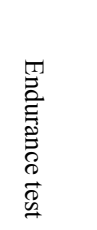 } & \multicolumn{3}{|c|}{ Pre-history of the material as a cable } \\
\hline & & $\begin{array}{l}\text { AC stress } \\
(\mathrm{kV} / \mathrm{mm})\end{array}$ & Temp. (K) & Time (h) \\
\hline US_a & $\mathrm{A}_{2}$ & - & 293 & - \\
\hline US_b & $\mathrm{A}_{2}, \mathrm{~B}$ & - & 293 & - \\
\hline E_Sla & $\mathrm{A}_{2}$ & 19.5 & 293 & 5000 \\
\hline E_S2a & $\mathrm{A}_{4}, \mathrm{~B}$ & 19.5 & 293 & 7747 \\
\hline E_S1b & $\mathrm{A}_{4}$ & 19.5 & 293 & 5581 \\
\hline E_S2b & $\mathrm{A}_{2}$ & 12.5 & 293 & 5000 \\
\hline _TS1a & $\mathrm{A}_{1,3}$ & 0 & 363 & 5000 \\
\hline _TS2a & $\mathrm{A}_{3}, \mathrm{~B}$ & 0 & 363 & 10000 \\
\hline ETS1a & $\mathrm{A}_{1}$ & 19.5 & 363 & 5000 \\
\hline ETS2a & $\mathrm{A}_{1,3}, \mathrm{~B}$ & 28 & 363 & 6000 \\
\hline ETS2a & $\mathrm{A}_{4}$ & 25 & 363 & 6000 \\
\hline ETS3a & $\mathrm{A}_{2}$ & 28 & 363 & 3000 \\
\hline ETS4a & $\mathrm{A}_{1}$ & 12.5 & 363 & 5000 \\
\hline SA & B & SERVICE & SERVICE & $\begin{array}{r}>18 \\
\text { YEARS }\end{array}$ \\
\hline
\end{tabular}

Table 1. Endurance test conditions.

\begin{tabular}{|c|c|c|c|}
\hline $\begin{array}{l}\text { Endurance } \\
\text { Test }\end{array}$ & $\begin{array}{c}\text { E-Field } \\
(\mathrm{kV} / \mathrm{mm})_{\mathrm{rms}}\end{array}$ & $\mathrm{AC}$ & $\begin{array}{l}\text { Temperature } \\
\left({ }^{\circ} \mathrm{K}\right)\end{array}$ \\
\hline $\mathrm{A}_{1,2,3 \& 4}$ & 70 & & 363 \\
\hline B & 55 & & 363 \\
\hline
\end{tabular}

The following equations are used to obtain the bounds of the $90 \%$ confidence intervals for the $p^{\text {th }}$ percentile [4]:

$$
\begin{aligned}
& t_{l}(p)=\alpha \exp \left\{Z_{l}(p) / \beta\right\} \\
& t_{u}(p)=\alpha \exp \left\{Z_{u}(p) / \beta\right\}
\end{aligned}
$$

Where:

$t_{l}(p)$ and $t_{u}(p)$ are the lower and upper bounds of the confidence interval for the $p^{\text {th }}$ percentile.

Confidence interval tables have been calculated in [4] and have been used in this study to estimate the $90 \%$ confidence limits according to the number of specimens used and failed/suspended for each test. In this study four specimens were used for each material $(n=4)$ and the test was terminated once three of them failed $(\mathrm{r}=3)$. The values for the factors $Z_{l}(p)$ and $Z_{u}(p)$ were extracted from the confidence interval figures in [4] for the percentiles $p=0.1 \%, 1.0 \%, 5.0 \%, 10 \%$, $30 \%$, and $95 \%$ and the bounds of $\alpha(63.2 \%)$ are also included for $n=4$ and $r=3$ as presented in Table 3 . 


\subsection{SAMPLE HANDLING}

Table 3: Factors $Z_{1}(p)$ and $Z_{u}(p)$ extracted from [4] in order to calculate the confidence limits for $\mathrm{n}=4$ and $\mathrm{r}=3$.

\begin{tabular}{c|cc}
\hline Percentile $p$ & $Z_{l}(p)$ & $Z_{u}(p)$ \\
\hline $0.1 \%$ & -15.1 & -2.3 \\
$1 \%$ & -9.9 & -1.1 \\
$5 \%$ & -6.4 & -0.65 \\
$10 \%$ & -4.84 & -0.415 \\
$30 \%$ & -2.431 & 0.08 \\
$63.21 \%(\alpha)$ & -1.17 & 0.99 \\
$95 \%$ & -0.55 & 2.98 \\
\hline
\end{tabular}

Such confidence limits enclose any particular percentile of the true population with $90 \%$ probability. The greater the number of specimens tested, the closer the upper and lower curves. Confidence intervals are also calculated for the shape parameter $\beta$, using the following equation:

$$
\begin{aligned}
& \beta_{l}=W_{l} \beta \\
& \beta_{u}=W_{u} \beta
\end{aligned}
$$

Where:

$\beta_{l}$ and $\beta_{u}$ are the lower and upper limits, respectively for the interval.

The factors $W_{l}$ and $W_{u}$ for $n=4$ and $r=3$ are obtained from [4] and are 0.456 and 4.67 respectively.

\subsection{MATERIALS}

All the materials used for the endurance tests were peelings of XLPE insulation with a thickness of $150 \mu \mathrm{m}$ but different stressing pre-histories as a cable, see Figure 1. The insulation for the cables was manufactured by two different companies, which can be distinguished by the small case letters, "a" and "b" in the reference name column in Table 2. The rest of the reference name of the materials under study is constructed according to acronyms of the stress that they experienced as a cable, i.e. US stands for Un-Stressed, ETS for ElectroThermally-Stressed and so on. Peelings from a service aged, SA, cable are also used for comparison. The same batch of XLPE was supplied to the cable manufacturers, thus the inherent differences between the insulation peelings, if any, come from the cable manufacturer's processes and the electrothermal stressing that they experienced as cables.

The peelings were thermally conditioned prior to the endurance testing. The conditioning occurred at $323 \mathrm{~K}$ at ambient pressure for 48 hours. The conditioning of the tapes was a feature of the ARTEMIS programme [2] to remove volatile by-products to ensure reproducible results [5].
In the ARTEMIS programme, one material supplier provided two cable manufactures with the same batch of XLPE resin in order to make model cables for Extra HighVoltage (EHV) with an insulation thickness of $14 \mathrm{~mm}$ corresponding to a $90 \mathrm{kV}$ cable construction, as shown in Figure 1a. After these cables had been electro-thermally stressed, the insulation was peeled (peeling thickness of 150 $\mu \mathrm{m})$ with a specially designed cryotome. The peelings were rolled into tapes with a width of $8 \mathrm{~cm}$ as is shown in Figure $1 \mathrm{~b}$ and were distributed to the rest of the ARTEMIS partners inside polyethylene-bags completely enclosed within aluminium bags, for investigation [3]. From then onwards the tapes were stored at a temperature around $278 \mathrm{~K}$ in order to prevent any further changes. The properties of the peelings were then investigated using samples taken from between 2 $\mathrm{mm}$ to $4 \mathrm{~mm}$ (or as close as possible to those margins) from the inner semiconductive screen. Figure 2 shows the sequence in time that each process took place in a rough scale.

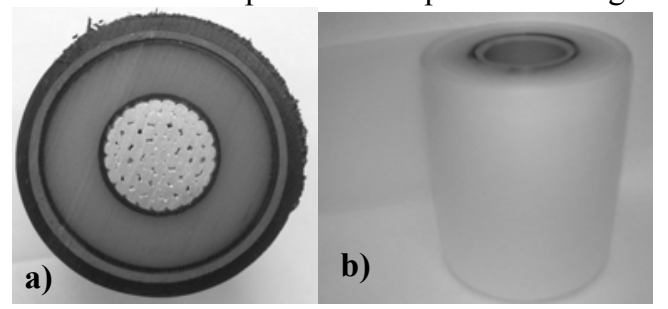

Figure 1. a) Section of the cable after any kind of stressing during the ARTEMIS programme and $b$ ) a tape roll after the insulation was peeled.

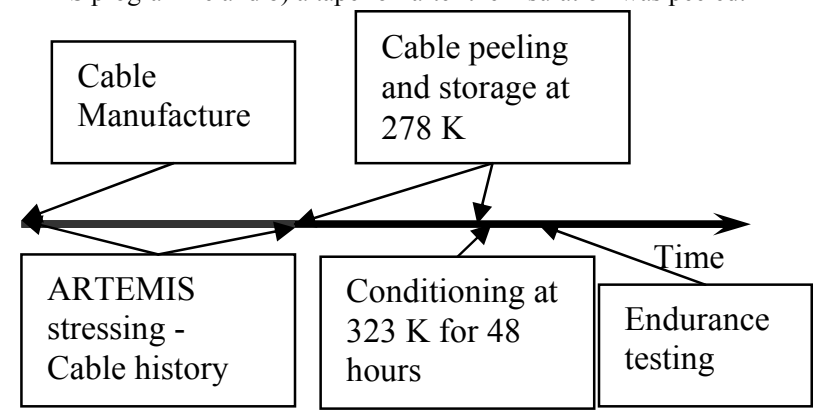

Figure 2. Time line of material used.

Before carrying out any experiments the samples were conditioned [4] (see Figure 2) so as to remove any volatile chemicals that are known to influence the behaviour of XLPE in an undefined manner [2].

After the conditioning process the samples used for the endurances tests $\mathbf{A}$ and $\mathbf{B}$ were placed between the electrodes and immersed in silicone oil as shown in Figure 3. The tray could accommodate up to four specimens of three different materials each, which means up to twelve specimens. In order to avoid air bubbles being trapped between the specimen and the electrode interfaces the whole tray was placed under vacuum till no air bubbles were observed and then was moved to the HV rig. The temperature was controlled via a Eurotherm controller at $363 \mathrm{~K}$. The specimens were not removed from the HV rig till three out of four samples failed 
for each material.

The time to breakdown was recorded by a high voltage circuit breaker with an accuracy of $1 / 100$ of an hour. Once a specimen failed the power was cut off for all the specimens. The specimen was identified using a Mega-ohm meter, and then isolated from the high voltage rig, so that the power could be switched back on by carefully ramping the voltage up to the desired value. This means that the failed specimen remained in the tray shown in Figure 3 till three specimens of all the materials have failed, as removing would disturb the remaining on-going specimens.

\subsection{ELECTRODE DESIGN}

The HV electrodes were brass of a cylindrical shape with a radius of $2.5 \mathrm{~cm}$, height of $3.0 \mathrm{~cm}$ and with rounded edges to minimize corona discharges. The bottom electrode was an aluminium plate with a thickness of $5 \mathrm{~mm}$, where up to four HV electrodes can be placed. A good contact was ensured by placing a Perspex glass plate with thickness of $5 \mathrm{~mm}$ above the brass electrodes and screwing the plate onto the electrodes, thereby pressing them onto the XLPE samples, see Figure 3.

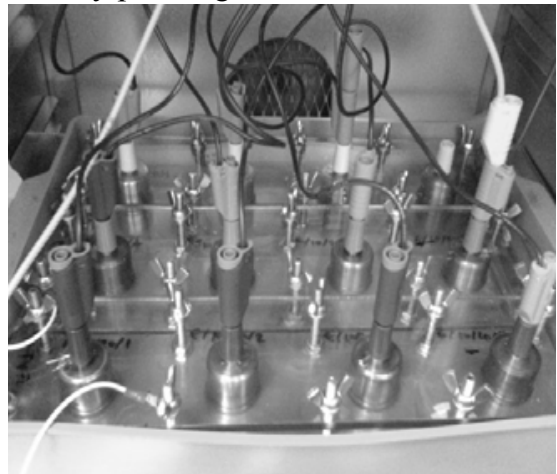

Figure 3. HV electrode set up at the start of an endurance test.

\section{RESULTS}

\subsection{HIGH ELECTRICAL AND THERMAL STRESS: ENDURANCE TEST A}

The results of the endurance test, which was carried out at an electric field of $70 \mathrm{kV} / \mathrm{mm}$ (rms) and a temperature of 363 $\mathrm{K}$, are shown in Figure 4. The estimated Weibull distribution for the samples with the most severe electro-thermal prehistory ETS2a is shown by the solid continuous line, together with its associated $90 \%$ confidence limits (dashed lines). The data of the ETS2a is represented in Figure 4 by filled triangles. In Figure 4, the filled solid symbols represent the materials that have been stressed as a cable for around $5000 \mathrm{~h}$ at $363 \mathrm{~K}$ and the unfilled ones represent the materials that have experienced no thermal stressing i.e. $\mathrm{T}=293 \mathrm{~K}$. It is observed that all the filled symbols lie within the $90 \%$ confidence limits of the most severely stressed material. However, the first failure of the 3000 hour electro-thermally pre-stressed material ETS3a, represented with the " $\boldsymbol{*}$ " symbol does lie within the limits although the other two lie outside. The endurance life of all the materials that experienced no stress or just electrical stress as a cable lie outside the $90 \%$ confidence limits, except for the first failure of the electrically pre-stressed material, E_S2a. Thus, the thermal stressing that the peelings had experienced as a cable seems to be the dominating process causing a reduction in their endurance life. The electric field levels that were applied to the XLPE cable insulation as a cable in the ARTEMIS programme seem to have no significant effect. The data from the samples with $3000 \mathrm{~h}$ of electro-thermal pre-history of stressing (ETS3b) indicates that this amount of time was insufficient to affect the material.

In general terms, the failures in Figure 4 can be separated into two groups with very similar statistical properties, one group with the filled symbols and another group with the hollow ones. The group with the filled solid symbols, indicated by the continuous-line circle, contains failures of samples

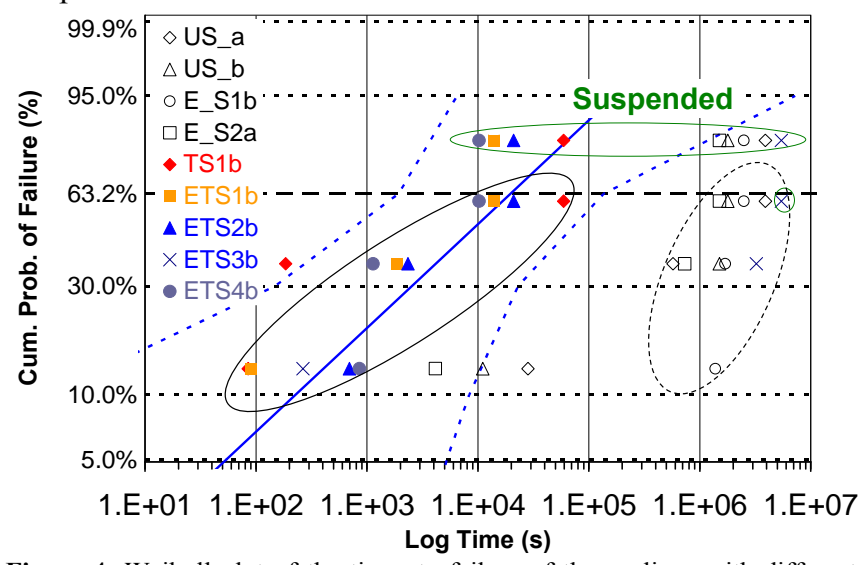

Figure 4. Weibull plot of the times to failure of the peelings with different electro-thermal histories as a cable, including data that was obtained during endurance tests $\mathrm{A} 1$ \& $\mathrm{A} 2$.

that have been stressed at least thermally $(363 \mathrm{~K})$ as a cable more than $5000 \mathrm{~h}$. The group with the unfilled symbols, grouped by the dashed circle, contains failures of samples that have experienced no stress or just electrical stress as a cable. The endurance lives of the samples from electro-thermally stressed cables are compared those from unstressed cables in Figure 5. This shows that the electro-thermal cable stressing has significantly reduced the ability of the insulation material to withstand electrical stress, resulting in a shift of the main part of the failure distribution to shorter lifetimes. The two data sets presented in Figure 5 are collations of life data from peelings from different cable/tape all of which had either experienced electro-thermal stress of varying magnitude or zero stress. The failures of the electro-thermally pre-stressed materials that are represented with the filled triangle in Figure 4 are used in conjunction with other endurance data from replicate tests on electro-thermally pre-stressed samples to form the failures of the electro-thermal data set. The suspended samples of each material set are censored. Both sets of materials have very similar shape parameter values, 
denoted on the figure as $\boldsymbol{\beta}$, but clearly very different characteristic values $\boldsymbol{\alpha}$. This plot implies that the electrothermal stressing carried out during the ARTEMIS programme did in fact alter the endurance capability of the materials with respect to the unstressed ones.

The characteristic values, $\alpha$, in conjunction with the corresponding $90 \%$ confidence limits of each material set that participated under the endurance test A are plotted in Figure 6. On the left hand-side of the black vertical line in Figure 6 the characteristic values are for materials with either unstressed or solely electrical stress histories as a cable and have very similar characteristic values. Materials with thermal and electro-thermal histories are shown on the right hand side of the black line and can be seen to have characteristic values that generally are less than those to the left. There are two sets of material characteristic encircled in black whose values are similar to the unstressed ones, and are therefore exceptions to the general trend. There are also materials with narrow confidence limits. These indicate that the failure generating feature possesses only a small sample-to-sample variation in these sample sets. One such set (ETS3b) has a short lifetime which suggests that it contains many severe defects of the same type, whereas the other is an exception to the general trend and hence has hardly any failure generating features.

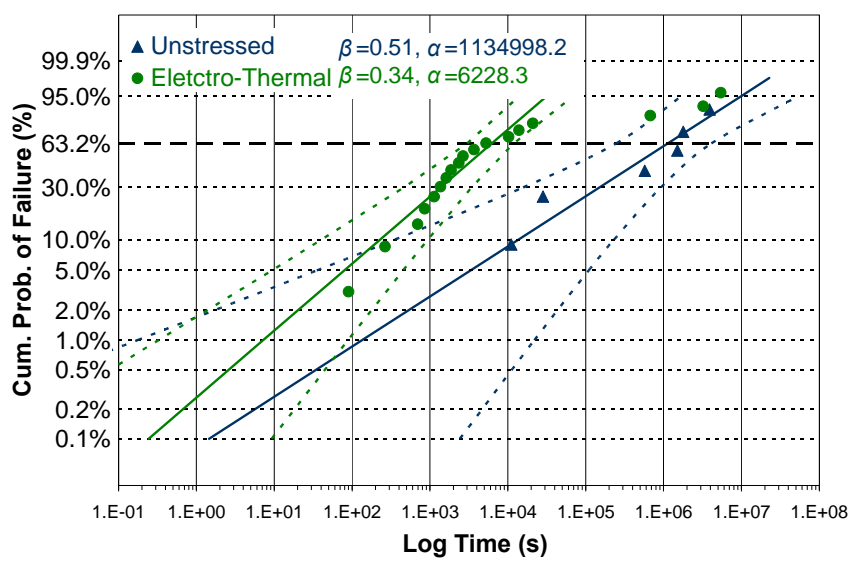

Figure 5. Comparison of the electro-thermally pre-stressed and unstressed (US) material failures that occurred during endurance test A. The $90 \%$ confidence limits of the Electro-Thermal data are estimated using only those failures enclosed by the $90 \%$ confidence limits.

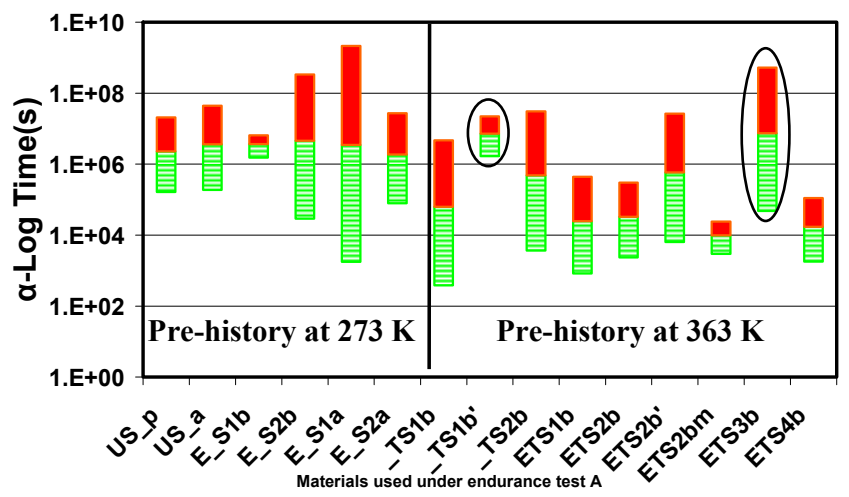

Figure 6. $90 \%$ confidence limits for the scale parameter $\alpha$. The horizontal line is the estimated value of $\alpha$ and is the separation point between the striped and the solid boxes.

\subsection{LOW ELECTRICAL AND HIGH THERMAL STRESS: ENDURANCE TEST B}

This test uses an ac field of $55 \mathrm{kV} / \mathrm{mm}$ (rms) and a temperature of $363 \mathrm{~K}$, and involves five sets of peelings with very distinct cable pre-histories in the ARTEMIS programme. These are peelings from: an unstressed, US b, an electrically, E_S2a, an electro-thermally, ETS2a, and a service stressed, SA cable. The failures of these materials are presented in Figure $7 \mathrm{~b}$. Eight failures have occurred by $1.8 \times 10^{7} \mathrm{sec}$, but only seven are presented in Figure $7 \mathrm{~b}$. The first failure of the service aged material was eliminated because it occurred immediately after switching on the voltage. The only material that had not failed by $1.8 \times 10^{7} \mathrm{sec}$ is the unstressed material. On the other hand two out of four specimens of the thermally stressed material as well as the electro-thermally and service stressed ones have failed. Regardless of the different electrical stresses that these three materials may have experience as a cable they all have experienced thermal stress at $363 \mathrm{~K}$ for samples from the ARTEMIS programme and $343 \mathrm{~K}$ or more for the service stressed material. Thus the effect of the stressing pre-history of the materials upon the endurance life follows the same trend as that found in endurance test $\mathbf{A}$ at high field and temperature,

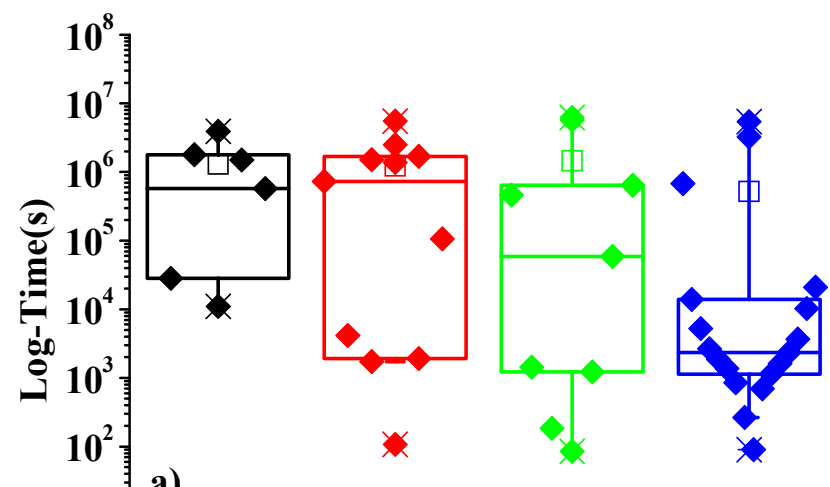

$10^{1}$ a)

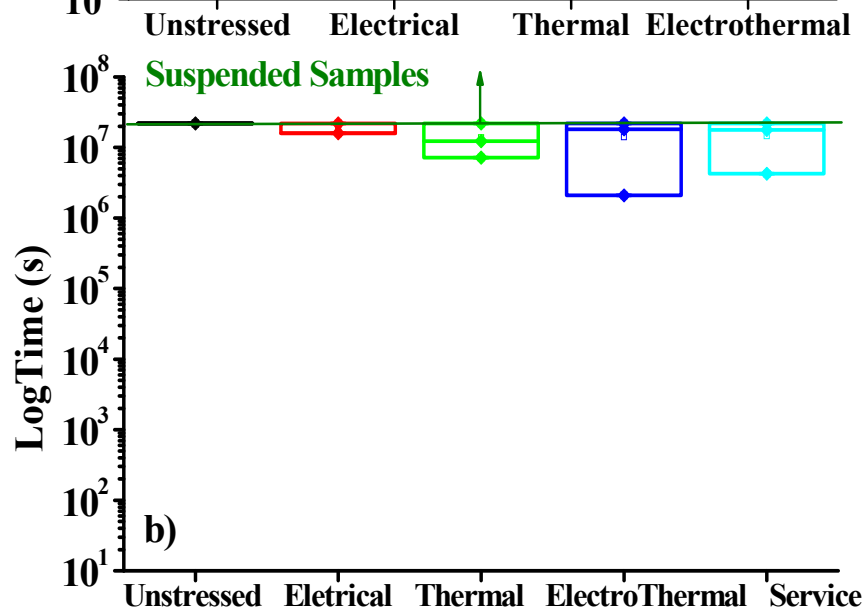

Figure 7. Box and whisker presentation of all the failures that occurred a) at $363 \mathrm{~K}$ and $70 \mathrm{kV} / \mathrm{mm}(\mathrm{rms}) \mathrm{b})$ at $363 \mathrm{~K}$ and $55 \mathrm{kV} / \mathrm{mm}(\mathrm{rms})$ of groups of 
materials not necessary from the same cable but having experienced the same type of cable stress.

where the materials with a thermal and electro-thermal stressing pre-history fail sooner than the others as is shown by the box and whiskers representation, given in Figure 7 . The box is determined by the $25^{\text {th }}$ and $75^{\text {th }}$ percentiles. The whiskers are determined by the $5^{\text {th }}$ and $95^{\text {th }}$ percentiles.

\section{DISCUSSION}

The endurance tests, $\mathrm{A}$ and $\mathrm{B}$, at high electrical fields (70 $\mathrm{kV} / \mathrm{mm}$ and $55 \mathrm{kV} / \mathrm{mm}$ ) and high temperature $(363 \mathrm{~K})$ showed that the pre-stressing history of the peelings as a cable did reduce the inherent endurance capability of the material especially when the pre-stressing was either just thermal or combination of electrical and thermal. These findings also agree with the endurance test data reported previously in [3]. Peelings with only an electrical pre-history did not demonstrate a significant decrease in the inherent endurance capability under these endurance tests. According to Figure 7 the influence of the pre-histories on the inherent endurance capability could be ranked from the least severe to the most severe one as follows:
$0 . \quad$ no stress
1. electrical stress
2. thermal stress
3. electro-thermal/service stress

The ranking suggests that electrical and thermal stress on their own seem to degrade the XLPE insulation less than both combined together. This suggestion also comes into an agreement with the thermodynamic based life models where the electrical field acts as an accelerator of the ageing process $[6,7]$. The influence of the pre-stressing histories on the cable peelings has also been detected by space charge measurements during the ARTEMIS programme $[2,8,9]$ and after the ARTEMIS programme [10-13]. Quantities that were extracted from space charge measurements on the pre-stressed cable peelings, such as dc injection voltage threshold, charge mobility and trap depth distribution were able to detect intrinsic degradation. Furthermore, the endurance data presented in this paper has identified the consequence of such changes. The statistical difference of the endurance test data can only be assigned to the intrinsic changes that occurred in the materials during cable stressing as the base resin that was used to manufacture the cables as well as the manufacturing and peeling process was identical in all cases.

The reasons that lead a dielectric insulation to age and ultimately fail are multiple as Dissado and Fothergill [1] have discussed. The theoretical models by Crine [14], Dissado et al [15], Mazzanti el al [7, 16], Paloniemi [17], Wu and Dissado [18] and Lewis et al [6], show that the attempt to describe it is very complex. These models approach a scientific explanation from different points of view; electrical, chemical, mechanical, electromechanical, etc, by the choice of the dominant mechanism that leads to failure. Nonetheless they all present a good fit to experimental data [7, 14, 19] and they all share a common characteristic; they are all dependent on temperature variations as well as the history of the polymeric materials that they attempt to describe. The dependence of the state of the polymeric materials on thermal exposure is an intrinsic phenomenon.

Much research [1] has been carried out in order to understand and evaluate the effect of temperature [20-22], on the material properties, such as crystallinity, conductivity, ability to accumulate and transport space charge [23, 24]. For example, Vaughan et al [25] found that the conductivity of the electrical trees that he studied changed when the temperature at which they were grown increased from 293 to $303 \mathrm{~K}$ under the same field conditions. The material properties of polyethylene and especially cross-linked polyethylene insulation may be strongly dependent on temperature for a number of reasons. Heating will lead to morphological changes such as modification of lamella thickness and interfaces. By-products from the cross-linking will move more easily within and out from the insulating layer and so any beneficial effects that they may have will be reduced. It should be noted that the conditioning applied to the cable peelings eliminates any potential effect of test temperature on this mechanism. Additives such as the antioxidant [26] can be consumed under continuous high thermal stress [24,27]. Therefore such additives may have lost their effectiveness during the period of cable stressing possibly allowing some regions of the cable insulation to become oxidised and/or chemically degraded. A spectroscopic analysis of cable crosssections has also shown that acrylates migrate from the semiconductor screens into the insulation with a migration rate and penetration depth that increases as the temperature increases [28]. Such migrating chemical species may locally alter the electrical properties of the insulating material. Each or all of these features in combination could have contributed to the reduction of the insulation life of the peelings from cables samples that had experienced a thermal stress component.

It is certain that electrical and thermal stress do influence the life time of polymeric insulation. Here it has been shown that under endurance testing conditions, polymeric materials that are exposed to thermal and electro-thermal pre-stressing are more susceptible to failure than those pre-stressed under electrical stress only. The endurance tests conducted at an electrical stress of $70 \mathrm{kV} / \mathrm{mm}$ (rms) caused failure, but there was no discernible evidence for lifetime differences due to the different pre-stressing electrical fields in the range up to $28 \mathrm{kV} / \mathrm{mm}$ (rms). Furthermore the pre-stressing at $363 \mathrm{~K}$ caused a reduction in endurance capability but pre-stressing at $293 \mathrm{~K}$ and $19.5 \mathrm{kV} / \mathrm{mm}$ showed no evidence for such a reduction. These findings raise two questions:

- Is there a threshold electrical stress for ageing?

- Is there a threshold thermal stress for ageing? 
and suggest that the answer is yes to both but further work is required in order to identify an accurate threshold for ageing.

\section{CONCLUSIONS}

This paper has reported on the effect of long-time electrical and thermal cable stresses upon the endurance capability of XLPE. This was investigated by subjecting a number of cable peelings with different stressing pre-histories to two endurance test conditions. The endurance tests were carried out at an ac electric field of 70 and $55 \mathrm{kV} / \mathrm{mm}$ (rms) both at $363 \mathrm{~K}$. The endurance data acquired was analyzed by Weibull statistics and suggests that the cable stressing during the ARTEMIS programme did degrade the insulation matrix as the inherent endurance capability of the peeling has been reduced. Different stressing pre-histories showed variations in the failure times. These are:

$>$ for the first $5000 \mathrm{~h}$ of electrical and electro-thermal stressing only cables that experienced a thermal component $(363 \mathrm{~K})$ showed evidence of significant ageing as expressed through a reduction in endurance life at $70 \mathrm{kV} / \mathrm{mm}$ and $363 \mathrm{~K}$;

$>$ for the same period of cable stressing there was no significant difference in endurance between samples from cables with different applied electrical fields, in the range from zero up to the maximum of 28 $\mathrm{kV} / \mathrm{mm}$. This was found to be the case for both cables stressed at 293 and $363 \mathrm{~K}$.

\section{ACKNOWLEDGMENT}

The authors would like to thank Dr. Nigel R. Hampton from the Georgia Tech National Electric Energy Testing Research and Applications Centre for his valuable contribution to preliminary discussions about this work. The authors would also like to thank the members of the ARTEMIS consortium for access to the samples from this project. A. Tzimas also thanks Borealis $\mathrm{AB}$ for financial support during the production of this work.

\section{ACKNOWLEDGMENT}

The authors would like to thank Dr. Nigel R. Hampton from the Georgia Tech National Electric Energy Testing Research and Applications Centre for his valuable contribution to preliminary discussions about this work. The authors would also like to thank the members of the ARTEMIS consortium for access to the samples from this project. A. Tzimas also thanks Borealis $\mathrm{AB}$ for financial support during the production of this work.

\section{REFERENCES}

[1] L. A. Dissado and J. C Fothergill, "Electrical Degradation and Breakdown in Polymers", Peter Peregrinus Ltd on behalf of IEE, 1992.
[2] J. C. Fothergill, G. C. Montanari, G. C. Stevens, C. Laurent, G. Teyssedre, L. A. Dissado, U. H. Nilsson, and G. Platbrood, "Electrical, microstructural, physical and chemical characterization of HV XLPE cable peelings for an electrical aging diagnostic data base," IEEE Trans. Dielectr. Electr. Insul, Vol. 10, pp. 514-27, 2003.

[3] A. Tzimas, M. Fu, L. A. Dissado, and R. N. Hampton, "Comparison of XLPE cable peelings with different electro-thermal histories using endurance test and residual charge methods," IEEE Intern. Conf. on Properties and Applications of Dielectric Materials, Bali, Indonesia, pp. 293-296, 2006

[4] J.C. Fothergill, R.N. Hampton and G.C. Montanari, "IEEE P930: the Statistical Analysis of Electrical Insulation Breakdown Data", IEEE Standard, 2003.

[5] L. A. Dissado, J. C. Fothergill, A. See, G. C. Stevens, L. Markey, C. Laurent, G. Teyssedre, U. H. Nilsson, G. Platbrood, and G. C. Montanari, "Characterizing HV XLPE cables by electrical, chemical and microstructural measurements on cable peeling: effects of surface roughness, thermal treatment and peeling location", IEEE Conf. on Electrical Insulation and Dielectric Phenomena (Cat. No.00CH37132), Victoria, BC, Canada, pp. 136-40, 2000.

[6] T. J. Lewis, J. P. Llewellyn, M. J. van der Sluijs, J. Freestone, and R. N. Hampton, "A new model for electrical ageing and breakdown in dielectrics" Dielectric Materials, Measurements and Applications, $7^{\text {th }}$ Intern. Conf. on (Conf. Publ. No. 430), pp. 220-224, 1996.

[7] G. Mazzanti, G. C. Montanari, and L. A. Dissado, "Electrical aging and life models: the role of space charge," IEEE Trans. Dielectr. Electr. Insul. vol. 12, pp. 876-890, 2005.

[8] G. Mazzanti, G. C. Montanari, and J. M. Alison, "A space-charge based method for the estimation of apparent mobility and trap depth as markers for insulation degradation-theoretical basis and experimental validation," IEEE Trans. Dielectr. Electr. Insul. vol. 10, pp. 187-97, 2003.

[9] G. Mazzanti, G. C. Montanari, and F. Palmieri, "Quantities extracted from space-charge measurements as markers for insulation aging," IEEE Trans. Dielectr. Electr. Insul. vol. 10, pp. 198-203, 2003.

[10] A. Tzimas, M. Fu, and L. A. Dissado, "Characterization of thermally aged XLPE cable peelings through space charge measurements", IEEE Conf. on Electrical Insulation and Dielectric Phenomena, Nashville, TN, USA, pp. 30-33, 2005.

[11] A. Tzimas, M. Fu, L. A. Dissado, U. H. Nilsson, and A. Campus, "Space charge characterization of XLPE peelings with a cable prehistory: Before and after AC endurance tests," IEEE Intern. Conf. on Solid Dielectrics, Winchester, United Kingdom, pp. 474-477, 2007.

[12] M. C. Lanca, M. Fu, E. Neagu, L. A. Dissado, J. Marat-Mendes, A. Tzimas, and S. Zadeh, "Comparative study of space charge in the polymeric insulation of power cables using PEA, isothermal and nonisothermal currents measurements," Proc. - Intern. Symp. on Electrets, Salvador, Bahia, Brazil, pp. 284-287, 2005.

[13] M. C. Lanca, M. Fu, E. Neagu, L. A. Dissado, J. Marat-Mendes, A. Tzimas, and S. Zadeh, "Space charge analysis of electrothermally aged XLPE cable insulation," Journal of Non-Crystalline Solids, vol. 353, pp. 4462-4466, 2007.

[14] J.-P. Crine, "On The Interpretation of Some Electrical Aging and Relaxation Phenomena in Solid Dielectrics". IEEE Trans. Dielectr. Electr. Insul. Vol. 12, pp. 1089-1107, 2005.

[15] L. A. Dissado, G. Mazzanti and G. C. Montanari, "The Role of Trapped Space Charges in the Electrical Aging of Insulating Materials". IEEE Trans. Dielectr. Electr. Insul. Vol. 4, pp. 496-506, 1997.

[16] G. Mazzanti, G. C. Montanari, and L. A. Dissado, "A space-charge life model for ac electrical aging of polymers". IEEE Trans. Dielectr. Electr. Insul. Vol. 6, pp. $864-875,1999$.

[17] P. Paloniemi, "Theory of Equalization of Thermal Ageing Processes of Electrical Insulating Materials in Thermal Endurance Tests I: Review of Theoretical Basis of Test Methods and Chemical and Physical Aspects of Ageing," IEEE Trans. on Electr. Insul. vol. EI-16, pp. 1-6, 1981.

[18] K. Wu and L. A. Dissado, "Percolation Model for Electrical Breakdown in Insulating Polymers". IEEE Conf. on Electrical Insulation and Dielectric Phenomena, pp. 514-518, 2004.

[19] C. L. Griffiths, J. Freestone, and R. N. Hampton, "Thermoelectric aging of cable grade XLPE". Conf. Record of the 1998 IEEE Intern. Symp. on Electr. Insul. vol.2, pp. 578-582, 1998. 
[20] G.C. Montanari and A. Motori, "Thermal endurance evaluation of XLPE insulated cables" Journ. of Phys. D (Appl. Phys.), vol. 24, pp. 1172-81, 1991.

[21] A. Boubakeur, Y. Mecheri and M. Boumerzoug, "Influence of continuous thermal ageing on the properties of XLPE used in medium voltage cables" $11^{\text {th }}$ Intern. Symp. on High Voltage Engineering (Conf Publ. No.467), vol.4, pp. 236-9, 1999.

[22] L. Boukezzi, A. Boubakeur, and M. Lallouani, "Effect of artificial thermal aging on the crystallinity of XLPE insulation cables: X-ray study," IEEE Conf. on Electrical Insulation and Dielectric Phenomena, pp. 65-68, 2007.

[23] L. Boudou and J. Guastavino, "Influence of temperature on low-density polyethylene films through conduction measurement". Journ. of Phys. D: Appl. Phys. Vol. 35, pp. 1555-1561, 2002.

[24] Y. L. Chong, G. Chen and Y. F. F. Ho, "Temperature Effect on Space Charge Dynamics in XLPE Insulation". IEEE Trans. Dielectr. Electr. Insul. Vol. 14, pp. 65-76, 2007.

[25] A. S. Vaughan, I. L. Hosier, S. J. Dodd, and S. J. Sutton, "On the structure and chemistry of electrical trees in polyethylene," Journ. of Phys. D (Appl. Phys.) vol. 39, pp. 962-78, 2006.

[26] A. Smedberg, B. Gustafsson, and T. Hjertberg, "What is crosslinked polyethylene?" Proc. of the 2004 IEEE Intern. Conf. on Solid Dielectrics, Vol.1, pp. 415-418, 2004.

[27] M. Fu, G. Chen, L.A. Dissado and J.C. Fothergill, "Influence of Thermal Treatment and Residues on Space Charge Accumulation in XLPE for DC Power Cable Application" IEEE Trans. Dielectr. Electr. Insul. Vol. 14, pp. 53-64, 2007.

[28] H. Herman, J. Thomas and G. Stevens "Spectroscopic and Chemometric Analysis of Cable Condition in the Artemis Program". Proc. of the 2004 IEEE Intern. Conf. on Solid Dielectrics, pp. 623-627, 2004.

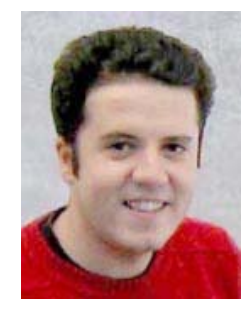

Antonios Tzimas was born in Volos, Greece in 1979. He received the BEng (2001) and MSc (2003) degrees in Electrical and Electronic Engineering from the University of Leicester where after completing his national service duties in Greece he returned to do research on the ageing properties of cross linked polyethylene. This was the topic of his Ph.D. thesis, he received the degree in 2008 . Since then he works in the national grid's high voltage laboratory at the University of Manchester as post Doctoral researcher investigating the ageing properties of outdoor composite insulators.

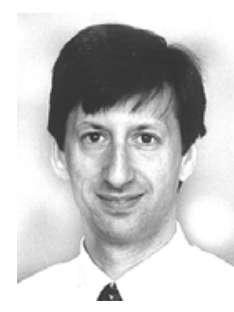

Simon M. Rowland (M'05) was born in London, England. He completed his BSc in Physics at UEA and his $\mathrm{PhD}$ at London University. He was awarded the IEE Duddell Premium in 1994 he became a FIEE in 2000. He has worked for many years on dielectrics and their applications. He has also been Operations and Technical Director in a multinational manufacturing company. He joined The School of Electrical and Electronic Engineering in The University of Manchester as a Senior Lecturer in 2003.

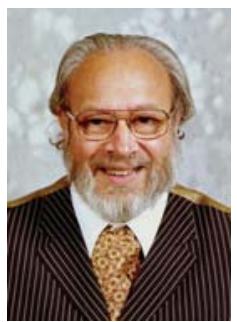

Leonard A. Dissado (SM'96-F'06) graduated from University College London with a degree in chemistry in 1963, obtained a Ph.D. degree in theoretical chemistry in 1966. After rotating between Australia and England twice, he settled in Chelsea College in 1977 to carry out research in dielectrics. Since then he has published many papers and one book, together with John Fothergill, on breakdown and associated topics. In 1995 he moved to the University of Leicester and was promoted to professor in 1998 . He has been a visiting professor at the University Pierre and Marie Curie in Paris, Paul Sabatier University in Toulouse, and Nagoya University, and a Senior Visiting Fellow at the Institute of Advanced Studies of the University of Bologna. He also has given numerous invited lectures, including the Whitehead Memorial Lecture in 2002. Currently he is an associate editor of the IEEE Transactions on DEI, and a member of DEIS AdCom. He obtained a D.Sc. degree in 1990 from London University. In 2007 he was honoured by the Universite Paul Sabatier, Toulouse, with the award of a Doctuer Honoris Causa, and in September 2008 with the award of Honorary Professor of Xi' an Jiaotong University, Xi'an, China.

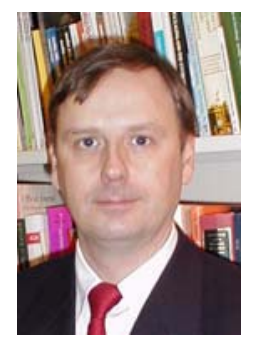

Ulf Nilsson was born in 1961. He received his master of science degree in engineering physics in 1987 at Lund Institute of Technology (Sweden). The focus was solid state physics especially silicon-based semiconductive technology. He joined Neste Polyeten AB in Stenungsund north of Gothenburg in 1987 responsible for electrical testing of polyethylene compounds for wire \& cable applications. This company later became part of the Borealis group. He is currently engaged in product development of power cable compounds and activities related to improved understanding of the performance of insulating and semiconductive materials under high ac and dc electric stress. 


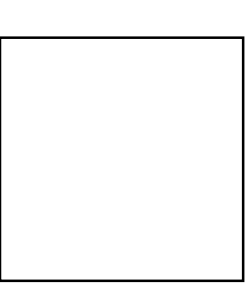

